\title{
Construção e validação da Escala de Lócus de Controle Parental na Saúde ${ }^{1}$
}

\author{
Márcia Maria Magrille de Cerqueira - Universidade Federal de Minas Gerais, Belo Horizonte, Brasil \\ Elizabeth do Nascimento2- Universidade Federal de Minas Gerais, Belo Horizonte, Brasil
}

\begin{abstract}
Resumo
O propósito da pesquisa foi adaptar para o contexto brasileiro uma escala de avaliação do lócus de controle parental na saúde. Inicialmente, foram realizadas as traduções direta e reversa da escala desenvolvida por Tinsley e Holtgrave (1989). Ao longo do processo de investigação (análise de juízes, semântica e psicométrica) verificou-se a necessidade de criação de novos itens, gerando uma nova escala, intitulada Escala de Lócus de Controle Parental na Saúde (LOCPS). Cada uma das etapas investigativas contou com uma determinada amostra. A amostra principal ficou constituída de 266 cuidadores (idade média=35,17 anos). Os 18 itens finais da LOCPS se mostraram discriminativos. Os índices de precisão (alfa de Cronbach) para as três dimensões da LOCPS ficaram entre 0,67 e 0,80. A validade fatorial indicou que a escala não é unidimensional. Estatísticas descritivas das pontuações são apresentadas para fins de referência para os profissionais que venham a utilizá-la.

Palavras-chave: Escala; Validade; Precisão.
\end{abstract}

\section{Construction and validation of Parental Health Locus of Control Scale}

\begin{abstract}
The purpose of this research was to adapt an assessment scale of the parental health locus of control to the brazilian context. Initially, direct and back translations of the scales developed by Tinsley and Holtgrave (1989) were done. Throughout the investigative process (judge, semantic and psychometric analyses) the need to create new items showed up leading to a new scale called Parental Health Locus of Control Scale (PHLCS). Each of the investigative stages had a particular sample. The main sample was constituted of 266 carers (average age $=35.17$ years old). The last 18 items of the PHLSC were discriminative. The accuracy ratings (Cronbach's alpha) for the three dimensions of the PHLCS were between 0.67 and 0.80 . The factor validity indicated that the scale is not unidimentional. Descriptive statistics of the ratings are depicted as a reference to those professionals who might want to use them.

Keywords: Scale;Validity; Reability.
\end{abstract}

\section{Introdução}

O lócus de controle, um construto vinculado à Teoria da Aprendizagem Social (Rotter, 1966), se refere às expectativas de controle que os indivíduos mantêm sobre os acontecimentos da vida diária. Indivíduos cuja orientação do lócus é interna acreditam poder exercer algum controle sobre esses acontecimentos; indivíduos cuja orientação é externa atribuem o controle dos acontecimentos a fatos externos - pessoas, entidades, destino, acaso ou sorte (Rotter, 1966, 1975, 1990). Entretanto, Rotter (1975) considera que o lócus de controle é somente um dos determinantes potenciais do comportamento e chama a atenção para a importância do valor do reforçamento. Toda predição de determinado comportamento deve levar em consideração o valor do reforçamento resultante para o indivíduo. Em suma, a ocorrência

\footnotetext{
${ }^{1}$ Este estudo é parte da pesquisa de dissertação de mestrado da primeira autora, intitulada "A influência de fatores demográficos e psicossociais sobre o engajamento dos cuidadores na dieta para as suas crianças fenilcetonúricas", desenvolvida no programa de PósGraduação em Psicologia da UFMG.

2 Endereço para correspondência: enasci@gold.com.br.
}

de determinado comportamento em qualquer situação psicológica específica é função da expectativa de que aquele comportamento levará a um reforçamento particular e do valor atribuído a tal reforçamento.

Desde a sua introdução na literatura psicológica, o lócus de controle tem sido considerado uma variável importante para a obtenção de metas futuras. No contexto da saúde, o construto é um dos mais amplamente investigados e existem evidências da sua importância para a qualidade de vida e o bem-estar dos indivíduos (Maisto \& German, 1981; Tinsley \& Holtgrave, 1989). Em relação a populações pediátricas, as investigações apontam para uma relação positiva entre a percepção de controle parental e o estado de saúde das crianças.

Maisto e German (1981) investigaram, em um estudo longitudinal, a relação entre o lócus de controle materno e o desenvolvimento de crianças portadoras de deficiência física e mental, as quais participavam de um programa de intervenção precoce. O desenvolvimento cognitivo, motor e da linguagem de 24 crianças $(12$ meninos e 12 meninas) com idade média de 10,7 meses foi avaliado. Quatro avaliações foram feitas durante o 
período no qual as crianças receberam a intervenção e uma avaliação ocorreu ao final do programa (follow-up), quando as mães responderam à Escala de Lócus de Controle (Rotter, 1966).

Os resultados mostraram que as expectativas de controle dos cuidadores, especificamente aquelas relacionadas à internalidade, explicaram $20 \%$ e $33 \%$ da variação nas habilidades das crianças em relação ao desenvolvimento da linguagem e ao desenvolvimento cognitivo, respectivamente, embora nenhuma relação entre o lócus de controle materno e o desenvolvimento motor das crianças tenha sido encontrada. De acordo com esses resultados, os autores sugerem que as expectativas de controle influenciam o controle que a mãe exerce, efetivamente, sobre o desenvolvimento da criança. Apesar dos resultados obtidos, é importante ressaltar o tamanho reduzido da amostra e a seleção não aleatória dos participantes, restrições estas impostas pelas próprias características do grupo estudado.

Tinsley e Holtgrave (1989) investigaram as relações entre o lócus de controle materno, a utilização dos serviços preventivos de saúde e o estado geral de saúde das crianças, utilizando uma escala que avalia as expectativas de controle dos pais sobre a saúde das crianças. Os resultados revelaram que a internalidade do lócus de controle materno relacionava-se com o número de consultas recebidas pela criança, com a imunização na data correta e com a taxa de vacinas recebidas pela criança, de acordo com a idade. Por sua vez, a efetivação das consultas e das vacinas na data correta, bem como o nível socioeconômico da mãe, relacionou-se negativamente com o número de doenças contraídas desde o nascimento. Os resultados revelaram que a percepção parental de controle interno sobre a saúde das crianças pode favorecer o uso adequado dos serviços preventivos, o que, por sua vez, exerce um efeito positivo sobre o estado geral de saúde da criança. Os autores chamam a atenção para a importância do uso de instrumentos específicos na investigação das crenças e das atitudes e dos seus efeitos sobre os comportamentos na saúde. Segundo Wallston, Wallston, Kaplan e Maides (1976), esses efeitos são multideterminados e altamente complexos, e instrumentos específicos podem ser mais sensíveis aos mesmos. Essa mesma advertência foi feita por Rotter em 1966, sendo novamente reforçada em 1975, ao esclarecer algumas concepções errôneas sobre o construto. É possível, também, que os efeitos das expectativas parentais sejam mais claramente compreendidos ao se investigar a expectativa do cuidador, especificamente em relação à saúde da criança, e não sobre a própria saúde ou a eventos em geral.

Em suma, as pesquisas revelam que a crença no exercício do controle (ou internalidade) é importante para o envolvimento dos indivíduos no estabelecimento e no alcance de metas, tanto em curto quanto em longo prazo. Embora outros determinantes exerçam papel fundamental na construção do caráter ativo dos indivíduos, é improvável, por exemplo, que um cuidador desempenhe ações favoráveis ao bem-estar físico e psicológico da sua criança se não acreditar que pode fazê-lo.

\section{Medidas de lócus de controle}

O lócus de controle foi originalmente avaliado por meio da Escala de Controle Interno Externo (Rotter, 1966), um instrumento que avalia as expectativas de controle dos indivíduos em uma ampla gama de situações da vida diária. A escala apresenta o formato de escolha forçada e os 29 itens são classificados em seis subcategorias: (1) reconhecimento acadêmico, (2) reconhecimento social, (3) amor e afeição, (4) dominância / ascendência, (5) crenças sociopolíticas e, (6) filosofia de vida. Após a publicação dessa escala e da advertência de Rotter sobre a sua generalidade, diversas outras escalas foram construídas para a investigação de expectativas de controle em domínios específicos.

Em revisão da literatura dos 25 anos passados, Furnham e Steele (1993) identificaram 66 instrumentos construídos para diferentes propostas de pesquisa: 28 relacionam-se à saúde, seis ao trabalho, sete a expectativas generalizadas, 15 destinam-se a diferentes faixas etárias e 10 foram desenvolvidos para diferentes propósitos de pesquisa. Os instrumentos relacionados à saúde investigam a percepção do controle em domínios relacionados à saúde geral, mental e bucal; controle do peso e da alimentação, diabetes, doenças coronárias, dor, ingestão de álcool, fumo, câncer, entre outros. Os autores identificam apenas duas escalas que investigam o lócus de controle parental da saúde das crianças: (1) Parental Locus of Control Scale (Furnham, 1991, citado por Furnham \& Steele, 1993), que investiga a extensão na qual os pais acreditam que eles próprios, outros poderosos ou a sorte exercem controle sobre o desenvolvimento geral das crianças, em todas as idades, e (2) The Parental Locus of Control Scale (Campis, Lyman e Prentice-Dunn, 1986, citados 
por Furnham \& Steele, 1993), que investiga as crenças de controle dos pais sobre os cuidados com crianças em idade escolar. As propriedades psicométricas dessas escalas não são relatadas pelos autores.

Embora não mencionada na revisão feita por Furnham e Steele (1993), Tinsley e Holtgrave (1989) desenvolveram uma escala que investiga as expectativas de controle dos pais sobre a saúde das crianças. A confiabilidade da escala foi de 0,96, medida por meio do procedimento de testereteste. A análise fatorial revelou uma estrutura de três fatores, a saber: (1) internalidade, (2) acaso, e (3) outros poderosos.

A proliferação de instrumentos para a avaliação do lócus de controle está intimamente relacionada com a definição dada ao construto (Rotter, 1966). É possível que um indivíduo apresente internalidade em um domínio particular como, por exemplo, no trabalho, mas atribua a fatores externos a qualidade da sua saúde. Em virtude dessa especificidade é desejável que a avaliação seja feita, também, em termos específicos, particularmente, quando o objetivo envolve o delineamento de programas de intervenção e modificação do comportamento.

\section{Escalas de lócus de controle adaptadas, construidas e validadas no Brasil}

Até o momento do presente estudo, encontrou-se na literatura brasileira a publicação de cinco escalas para a avaliação do lócus de controle. Essas escalas relacionam-se aos seguintes domínios: eventos gerais da vida cotidiana, casamento, ambiente organizacional e saúde.

A Escala Multidimensional de Lócus de Controle de Levenson foi adaptada para uso no contexto brasileiro por Dela Coleta (1987) e, posteriormente, avaliada quanto à validade fatorial por Tamayo (1989). A escala é composta de três subescalas (Internalidade, Externalidade - Outros poderosos e Externalidade - Acaso), cada uma contendo oito itens. Os resultados da análise da precisão foram, respectivamente, 0,54 e 0,50 para a subescala I; 0,66 e 0,62 para a subescala $O P$ e 0,65 e 0,63 para a subescala $A$. A investigação da validade fatorial da escala identificou que a estrutura tridimensional proposta pelos estudos iniciais de Levenson foi confirmada para a amostra brasileira. Em virtude de a precisão ter sido fraca não somente na versão brasileira, mas também na original - o uso da escala é satisfatório para a pesquisa básica, mas deixa a desejar na psicologia aplicada.
Outra escala adaptada para o uso no contexto brasileiro por Dela Coleta (1992) foi a Escala de Lócus de Controle Conjugal (Miller, Lefcourt \& Ware, 1983, citado por Dela Coleta, 1992). Quatro dimensões envolvendo a atribuição das conseqüências derivadas da vida conjugal são abordadas: (1) habilidade, (2) esforço, (3) acaso ou sorte, e (4) características contextuais incontroláveis. Um escore global é obtido e aumenta em função da externalidade do lócus de controle conjugal. Dois estudos foram realizados. $O$ índice de confiabilidade obtido para a amostra brasileira $(0,75)$ foi semelhante ao do estudo original $(0,83)$. O alfa de Cronbach foi de 0,89 para a subescala Satisfação com a interação conjugal; de 0,81 para a subescala denominada Aspectos Estruturais e de 0,75 para a subescala que avalia a Satisfação com os aspectos emocionais do cônjuge. A soma total dos escores apresentou índice de confiabilidade de 0,91. A análise fatorial confirmou a composição de cada escala. Os índices psicométricos obtidos indicam que a escala é adequada para a avaliação do lócus de controle conjugal no contexto brasileiro.

La Rosa (1991) construiu uma escala de lócus de controle generalizado, a qual avalia crenças sobre a internalidade instrumental, a alienação sociopolítica, o controle por poderosos do macro sistema social e pela sorte e o controle por poderosos do micro sistema social. Em três estudos realizados, a análise fatorial revelou uma estrutura com os quatro fatores propostos. Os índices de consistência interna para cada fator e para a escala variaram entre 0,78 e 0,88 . Correlações itens-escala ( $\mathrm{r}$ de Pearson) também foram realizadas, e os índices ficaram entre $0,38 \mathrm{e}$ 0,73. A escala pode ser usada em amostras masculinas, femininas ou mistas.

Com a finalidade de investigar o lócus de controle organizacional, a Escala de Lócus de Controle Organizacional (ELCO) foi construída e validada por Pasquali, Alves e Pereira (1998). A escala, composta por 28 itens, tem como referência a teoria de Rotter e a Escala Mutidimensional de Lócus de Controle de Levenson (Dela Coleta, 1987). Análises fatoriais confirmatórias revelaram dois fatores, a saber: (1) externalidade (composto por 18 itens), e (2) internalidade (composto por 10 itens). Os índices de confiabilidade (alfa de Cronbach) foram de 0,81 para a subescala "internalidade" e 0,66 para a subescala "externalidade". Segundo os autores, esses resultados indicam que a escala deixa a desejar no que se refere à consistência interna. Em 
virtude dos resultados obtidos, o uso da escala nesse contexto deve ser feito com cautela.

Para avaliar o lócus de controle de pacientes portadores de insuficiência renal crônica, Peres (1993) adaptou e validou uma escala multidimensional. Composta por 18 itens no formato Likert, a escala apresenta três dimensões: (1) internalidade, (2) externalidade - outros poderosos, e (3) externalidade - acaso, sorte, destino; cada uma com seis itens. A validade de conteúdo da escala foi estabelecida por meio da análise de juízes. O coeficiente alfa foi de 0,73 para a escala como um todo. Para cada uma das subescalas, os coeficientes obtidos foram de 0,72 (internalidade), 0,68 (externalidade - outros poderosos) e de 0,64 (internalidade - acaso/sorte). Não foram feitas análises para a investigação dos fatores propostos.

Como se observou, nenhuma escala que investigue o lócus de controle dos pais em relação à saúde das suas crianças foi disponibilizada, até o presente momento, para uso no contexto brasileiro. Entretanto, evidências apóiam a existência de uma relação positiva e significativa entre as expectativas parentais de controle da saúde das crianças e o estado real de saúde das mesmas (Maisto \& German, 1981; Tinsley \& Holtgrave, 1989). Uma vez que as evidências disponíveis na literatura se referem a estudos feitos em outros contextos, a investigação dessa relação no contexto brasileiro se faz necessária. Para tanto, inicialmente os autores do presente estudo optaram pela adaptação da Parental Health Beliefs Scales. No entanto, diante do número substantivo de modificações do conjunto de itens original, o instrumento passou a configurar uma nova escala. Uma das razões que justificam a elaboração de uma escala como a LOCPS é a inexistência, no Brasil, de um instrumento que avalie as crenças parentais relacionadas à saúde das crianças. Escalas como a aqui proposta, oferecem a oportunidade, para os profissionais da área da saúde, de identificar pais que estejam em risco de não se engajar no tratamento de suas crianças, principalmente daquelas que necessitam de cuidados prolongados em virtude de problemas crônicos de saúde, além de propiciar a elaboração de estratégias de intervenção específicas.

\section{Método}

\section{Participantes}

Tendo em vista o objetivo proposto, o estudo contou com diferentes amostras para cada uma das três etapas realizadas. Para a análise de juízes, participaram nove professores universitários envolvidos em pesquisas sobre o tema. Na etapa da análise semântica dos itens, participaram 20 mães, $50,0 \%$ delas possuindo até o ensino médio e a outra metade o nível superior. Finalmente, na terceira etapa, a amostra ficou constituída de 266 cuidadores com idades entre 18 e 76 anos (média $=35,17$; desvio padrão $=8,47$ ) e com diferentes níveis de escolaridade (Tabela 1). Para o estudo sobre a validade de critério, foi constituída uma subamostra de 82 mulheres.

\section{Instrumentos}

Para a elaboração do conjunto inicial de itens da Escala de Lócus de Controle Parental na Saúde (LOCPS), procedeu-se a uma revisão da literatura existente de modo a viabilizar a operacionalização comportamental do construto e a sua representação empírica. Os 20 itens inicialmente elaborados foram inspirados na escala desenvolvida por Tinsley e Holtgrave (Tinsley \& Holtgrave, 1989), por meio do procedimento de tradução e tradução reversa (back translation). Alguns itens foram adaptados de modo a refletir o contexto brasileiro, e novos itens foram elaborados. Após as análises psicométricas (apresentadas na seção de resultados) a versão final da escala ficou constituída de 18 itens (Anexo).

A escala foi elaborada de forma a contemplar três dimensões, com seis itens cada. As dimensões são: Internalidade (I), que avalia o grau em que o sujeito acredita controlar a sua vida; Outros poderosos (OP), que avalia a crença de que este controle está nas mãos de pessoas poderosas e Acaso/sorte (A), que avalia a crença de ser controlado pelo acaso, pela sorte ou destino.

Em formato tipo Likert, a escala oferece cinco opções de resposta para cada afirmativa, as quais vão desde discordo totalmente (1) até concordo totalmente (5). A tarefa do sujeito consiste em escolher, dentre essas opções, aquela que melhor representa o grau da sua crença. A aplicação pode ser feita na forma individual ou coletiva e a duração média para a realização é de 15 minutos, embora não haja limite de tempo para resposta. As instruções para aplicação, baseadas em instruções de escalas semelhantes, foram elaboradas pela autora.

A correção da escala é feita através da fórmula: IT=I-(OP + A / 2), onde IT representa a internalidade total; I, a pontuação obtida por meio da soma dos itens correspondentes à 
dimensão internalidade; OP a pontuação obtida por meio da soma dos itens correspondentes à dimensão outros poderosos e A a pontuação obtida por meio da soma dos itens correspondentes à dimensão acaso/sorte.

Para o estudo de validade de critério foi utilizada a Escala Multidimensional de Lócus de Controle de Levenson (Levenson, 1973), adaptada para uso no contexto brasileiro por Dela Coleta (1987). A escala é composta de 24 itens e avalia a internalidade (I), outros poderosos (OP) e acaso (A). Oferece cinco opções de resposta, desde (1) concordo totalmente até (5) discordo totalmente.
A pontuação varia entre 8 e 40 , e quanto maior o escore em cada escala, maior a expectativa de controle pela fonte correspondente.

Para a condução da análise de juízes, foi elaborado um formulário contendo a definição operacional do construto, os itens propostos e as instruções para sua análise. A avaliação dos itens incluiu os seguintes quesitos: (1) adequação do conteúdo, (2) identificação do lócus do controle, (3) a pertinência, (4) a relevância; e (5) a adequação da formulação. O formulário também incluiu espaço para que os juízes apresentassem sugestões.

Tabela 1 - Amostra para o estudo de validação da Escala de Lócus de Controle Parental na Saúde.

\begin{tabular}{|c|c|c|c|c|}
\hline \multirow{2}{*}{$\begin{array}{l}\text { Características } \\
\text { Cuidador }\end{array}$} & \multicolumn{2}{|c|}{ Cuidadores de crianças fenilcetonúricas } & \multicolumn{2}{|c|}{ Cuidadores de crianças saudáveis } \\
\hline & \multicolumn{2}{|c|}{$\mathrm{N}=117$} & \multicolumn{2}{|l|}{$\mathrm{N}=149$} \\
\hline & Mãe & $99(84,6 \%)$ & Mãe & $130(87,2 \%)$ \\
\hline & Pai & $10(08,6 \%)$ & Pai & $15(10,1 \%)$ \\
\hline & Outros & $08(06,8 \%)$ & Outros & $4(02,7 \%)$ \\
\hline \multirow[t]{2}{*}{ Idade } & Média \pm DP & $34,76 \pm 10,06$ & Média \pm DP & $35,5 \pm 6,9$ \\
\hline & Variação & $24-76$ & Variação & $18-65$ \\
\hline \multirow[t]{2}{*}{ Residência } & $\begin{array}{l}\text { Belo Horizonte e região } \\
\text { metropolitana }\end{array}$ & $21(17,9 \%)$ & $\begin{array}{l}\text { Belo Horizonte e região } \\
\text { metropolitana }\end{array}$ & $145(97,3 \%)$ \\
\hline & Interior de Minas Grais & $96(82,1 \%)$ & $\begin{array}{l}\text { Interior de Minas Gerais } \\
\text { Espírito Santo }\end{array}$ & $\begin{array}{l}02(1,3 \%) \\
02(1,3 \%)\end{array}$ \\
\hline Nível & BI (baixo inferior) & $15(12,8 \%)$ & BI (baixo inferior) & $01(0,7 \%)$ \\
\hline \multirow[t]{3}{*}{ socioeconômico* } & BS (baixo superior) & $66(56,4 \%)$ & BS (baixo superior) & $13(08,7 \%)$ \\
\hline & MI (médio inferior) & $32(27,4 \%)$ & MI (médio inferior) & $66(44,3 \%)$ \\
\hline & M (médio) & $04(03,4 \%)$ & M (médio) & $69(46,3 \%)$ \\
\hline \multirow[t]{4}{*}{$\begin{array}{l}\text { Nível de } \\
\text { Escolaridade }\end{array}$} & $\begin{array}{l}\text { Analfabeto / semi- } \\
\text { analfabeto }\end{array}$ & $03(02,5 \%)$ & $\begin{array}{l}\text { Analfabeto / semi- } \\
\text { analfabeto }\end{array}$ & --- \\
\hline & Ensino Básico & $62(53,0 \%)$ & Ensino Básico & $08(5,4 \%)$ \\
\hline & Ensino Médio & $34(29,0 \%)$ & Ensino Médio & $37(24,8 \%)$ \\
\hline & Ensino Superior & $18(15,4 \%)$ & Ensino Superior & $104(69,8 \%)$ \\
\hline
\end{tabular}

Nota. *Classificação socioeconômica conforme questionário disponível em Souza (1995).

\section{Procedimentos de coleta e análise dos dados}

Para a análise de juízes, 15 professores universitários foram contatados via e-mail e convidados a participar do estudo. Os nove professores que aceitaram participar como juízes receberam o formulário de avaliação dos itens propostos. Os dados foram analisados considerando cada um dos quesitos avaliados e as sugestões apresentadas para reformulação dos itens. O critério para a manutenção do item na escala foi a obtenção de pelo menos $80 \%$ de concordância entre os juízes em cada um dos quesitos (Pasquali, 1999).

Após a análise dos juízes, procedeu-se a uma análise semântica, cujo objetivo foi verificar a compreensão dos itens por membros da população-alvo. As mães foram informadas dos objetivos do estudo e entrevistadas, após a concordância em participar e assinatura do Termo de Consentimento Livre e Esclarecido. As entrevistas foram realizadas individualmente e em grupos de no máximo três participantes. Os itens foram lidos em voz alta pelo examinador e cada participante foi solicitado a julgá-los em função da sua inteligibilidade. Sugestões para reformulações e/ou construção de novos itens foram registradas.

A versão piloto foi aplicada para investigação dos parâmetros psicométricos dos itens e da escala. Para análise dos itens calculou-se a correlação item-total $\left(r_{i t}\right)$, enquanto uma medida do grau de discriminação dos itens. Foram considerados discriminativos os itens que apresentaram correlação item-total superior a 0,25. $\mathrm{O}$ cálculo do coeficiente de consistência interna 
por meio do alfa de Cronbach permitiu estimar a precisão das subescalas. Para a investigação da validade foram realizadas análises fatoriais exploratórias com o objetivo de avaliar o grau de representatividade dos construtos. Para tanto, verificou-se: a fatorabilidade da matriz por meio do KMO; o número e tamanho dos eigenvalues (autovalores) maiores ou iguais a 1,0 ; as cargas fatoriais dos itens nos fatores e o significado teórico dos fatores. Em um primeiro momento foram realizadas análises dos componentes principais com e sem rotação (direct oblimin). Investigou-se também a validade por meio da análise de correlação entre o desempenho na escala proposta e na Escala Multidimensional de Lócus de Controle de Levenson.

\section{Resultados}

\section{Análise de juizes}

A maioria dos itens inicialmente propostos (15 dos 20 itens, num total de $75 \%$ ) encontrou o critério de $80 \%$ de concordância entre os avaliadores em todos os quesitos avaliados. Um item foi eliminado e oito foram reformulados e mantidos segundo sugestões dos avaliadores. Dentre os oito itens reformulados, dois não alcançaram a concordância em todos os quesitos avaliados, mas foram mantidos após reformulação, conforme indicação, pelos juízes, da pertinência e relevância dos mesmos para a investigação. Ainda em face de sugestões oferecidas, 22 itens alternativos foram adicionados à escala.

\section{Análise semântica}

Os 19 itens resultantes da análise de juízes, em conjunto com os 22 novos itens, num total de 41, foram submetidos à análise semântica e avaliados por 20 mães. Após a análise, 12 permaneceram inalterados, seis foram reformulados, quatro novos itens foram construídos e os 23 restantes, excluídos. A reformulação e a exclusão de itens basearam-se na detecção de ambigüidades na formulação e na presença de palavras de difícil compreensão. A elaboração de novos itens baseou-se em sugestões pertinentes oferecidas pelas participantes.

A versão piloto da escala passou a apresentar um total de 22 itens. Destes, sete se referem à dimensão "internalidade", oito à "externalidade-acaso/sorte" e sete à "externalidade-outros poderosos". Essa versão foi aplicada na terceira amostra do presente estudo, que ficou constituída de cuidadoras de crianças fenilcetonúricas e de crianças saudáveis, conforme apresentado na Tabela 1.

\section{Análise psicométrica dos itens e da escala}

A investigação do grau de discriminação dos itens foi realizada para cada uma das três dimensões, uma vez que o estudo da validade de construto por meio de análises fatoriais exploratórias apontou que a escala não é unidimensional. $\mathrm{Na}$ dimensão internalidade as correlações variaram entre 0,28 e 0,62 , indicando que apenas o item 2 mostrou-se pouco discriminativo. $\mathrm{Na}$ dimensão externalidade - acaso sorte, nenhum item obteve correlação item-total inferior a 0,30 e as correlações variaram entre 0,37 e 0,65 . Finalmente, na dimensão externalidade outros poderosos, o item 12 apresentou pouca capacidade para discriminar as pessoas em relação a essa dimensão $(0,25)$. Os itens restantes representantes dessa dimensão apresentaram correlações item-total superiores a 0,30 ( $\mathrm{r}_{\mathrm{it}}$ máxima igual a 0,50). Diante de tais resultados, optou-se por excluir os itens 2 (Não há nada que eu possa fazer para evitar que meu filho adoeça) e 12 (Somente os dentistas podem cuidar dos dentes do meu filho), cabendo destacar que o item 2 já havia sido considerado inadequado, segundo a avaliação dos juízes. Em face da recomendação de que a investigação das propriedades psicométricas dos itens também contemple os resultados das análises fatoriais da escala, verificou-se com base em tais análises que, além dos itens 2 e 12, outros dois itens também não se mostraram adequados, enquanto representantes das dimensões para as quais foram construídos, a saber: os itens 1 (A saúde do meu filho depende da sorte) e 10 (Acidentes normalmente acontecem às crianças). Ao proceder novo cálculo das correlações itemtotal para os 18 itens finais, apenas o item 11 (Posso fazer muitas coisas para lutar contra as doenças do meu filho) apresentou índice de discriminação ligeiramente inferior a 0,30 . No entanto, optou-se por mantê-lo na escala pelas seguintes razões: a) garantir a abrangência de conteúdo; b) manter o equilíbrio nas três dimensões quanto ao número de itens e; c) ter apresentado carga fatorial igual a 0,50 no fator para o qual foi construído, a internalidade. $\mathrm{Na}$ Tabela 2 é possível observar que as correlações item-total em cada dimensão variaram entre 0,29 e 0,65 . 
Tabela 2 - Características psicométricas dos itens da Escala Lócus de Controle Parental na Saúde (LOCPS).

\begin{tabular}{|c|c|c|c|c|c|c|}
\hline Dimensão & Conteúdo do item & $\overline{r_{i t}}$ & F1 & F2 & F3 & $h^{2}$ \\
\hline \multirow[t]{6}{*}{ Internalidade } & $\begin{array}{l}\text { Posso fazer muitas coisas para que meu filho fique } \\
\text { bom quando ele adoece. }\end{array}$ & 0,36 & & 0,65 & & 0,45 \\
\hline & $\begin{array}{l}\text { Posso fazer muitas coisas para manter a saúde do } \\
\text { meu filho. }\end{array}$ & 0,65 & & 0,84 & & 0,70 \\
\hline & $\begin{array}{l}\text { A saúde do meu filho depende, em grande parte, de } \\
\text { como eu cuido dele. }\end{array}$ & 0,29 & & 0,50 & & 0,27 \\
\hline & $\begin{array}{l}\text { Posso fazer alguma coisa para evitar que meu filho } \\
\text { tenha cáries. }\end{array}$ & 0,37 & & 0,52 & & 0,33 \\
\hline & $\begin{array}{l}\text { Posso fazer muitas coisas para evitar que meu filho } \\
\text { sofra acidentes. }\end{array}$ & 0,52 & & 0,71 & & 0,52 \\
\hline & $\begin{array}{l}\text { Posso tomar cuidados para que meu filho tenha uma } \\
\text { boa alimentação. }\end{array}$ & 0,41 & & 0,58 & & 0,37 \\
\hline $\begin{array}{l}\text { Externalidade } \\
\text { - outros }\end{array}$ & $\begin{array}{l}\text { Sempre que meu filho passa mal, o melhor a fazer é } \\
\text { levá-lo imediatamente a um hospital. }\end{array}$ & 0,47 & & & $-0,73$ & 0,51 \\
\hline \multirow[t]{5}{*}{ poderosos } & $\begin{array}{l}\text { Confio inteiramente no médico, ele estudou e sabe o } \\
\text { que é melhor para a saúde do meu filho. }\end{array}$ & 0,31 & & & $-0,50$ & 0,29 \\
\hline & $\begin{array}{l}\mathrm{Na} \text { maioria das vezes, quem pode cuidar dos dentes } \\
\text { do meu filho são os dentistas. }\end{array}$ & 0,46 & & & $-0,63$ & 0,42 \\
\hline & $\begin{array}{l}\text { Quando meu filho se machuca, o melhor a fazer é } \\
\text { levá-lo ao médico. }\end{array}$ & 0,51 & & & $-0,75$ & 0,57 \\
\hline & $\begin{array}{l}\mathrm{Na} \text { maioria das vezes, quem pode evitar que meu } \\
\text { filho fique doente são os médicos e as enfermeiras. }\end{array}$ & 0,39 & 0,32 & & $-0,38$ & 0,36 \\
\hline & $\begin{array}{l}\text { É papel dos nutricionistas garantir que meu filho } \\
\text { tenha uma alimentação saudável. }\end{array}$ & 0,44 & & & $-0,50$ & 0,37 \\
\hline Externalidade & A saúde do meu filho depende da sorte. & 0,61 & 0,76 & & & 0,58 \\
\hline \multirow[t]{5}{*}{ - acaso/sorte } & $\begin{array}{l}\text { Não importa o que eu faça, meu filho fica doente } \\
\text { por falta de sorte. }\end{array}$ & 0,57 & 0,77 & & & 0,55 \\
\hline & Crianças que nunca adoecem contam com a sorte. & 0,63 & 0,82 & & & 0,64 \\
\hline & $\begin{array}{l}\text { Os acidentes que acontecem com as crianças são } \\
\text { obra do destino. }\end{array}$ & 0,51 & 0,65 & & & 0,44 \\
\hline & $\begin{array}{l}\text { Se meu filho tem azar, nada que eu ou os médicos } \\
\text { façam pode evitar que ele fique doente. }\end{array}$ & 0,52 & 0,53 & & & 0,45 \\
\hline & $\begin{array}{l}\text { Se meu filho tem que adoecer, ele adoece e não há } \\
\text { nada nem ninguém que possa evitar. }\end{array}$ & 0,50 & 0,47 & & & 0,41 \\
\hline $\mathrm{KMO}$ & 0,81 & & & & & \\
\hline Eigenvalue & & & 4,25 & 2,61 & 1,36 & \\
\hline \% variância & & & 23,62 & 14,47 & 7,56 & \\
\hline Alfa & & & 0,80 & 0,67 & 0,70 & \\
\hline $\mathrm{N}^{\circ}$ de itens & & & 6 & 6 & 6 & \\
\hline
\end{tabular}

A investigação da validade de construto por meio da análise fatorial exploratória permitiu identificar que a matriz de correlações era passível de fatoração $(\mathrm{KMO}=0,81)$, com possibilidade de extração de até cinco componentes (eigenvalue $\geq 1,0)$. Os três primeiros componentes explicaram 45,66\% da variância e constituíram a melhor solução fatorial para o conjunto de itens. Cada dimensão da escala ficou representada empiricamente pelos itens propostos teoricamente para representá-la (Tabela 2). Em geral, as cargas fatoriais dos itens foram altas, particularmente as dos itens da dimensão externalidade - acaso/sorte. Apenas o item 18 apresentou carga fatorial superior a 0,30 nas duas dimensões de externalidade, embora represente mais a dimensão outros poderosos que acaso/sorte. Conforme era esperado, as duas dimensões de externalidade correlacionam-se significativamente $(r=-0,35)$. As correlações dessas dimensões de externalidade (acaso/sorte e outros poderosos) com internalidade foram fracas $(-0,19$ e $-0,02$, respectivamente). Os índices de precisão de cada dimensão variaram entre 0,67 e 0,80 (Tabela 2), 
indicando adequada consistência interna, conforme Pietro e Muñiz (2000).

A análise de correlação entre as pontuações na LOCPS e na Escala de Levenson foi conduzida com a finalidade de levantar evidências de validade da primeira, já que ambas propõem medir o construto lócus de controle. Os resultados indicaram que todas as correlações entre as pontuações no índice geral de internalidade e entre as dimensões (internalidade, externalidade outros poderosos e externalidade acaso/sorte) foram significativas do ponto de vista estatístico $(\mathrm{p}<0,05)$ e moderadas a fracas quanto à magnitude (Dancey \& Reidy, 2006). As correlações apresentadas foram: 0,$45 ; 0,28 ; 0,38$ e 0,57 ; respectivamente. Diante do exposto, verifica-se que as escalas avaliam construtos semelhantes, embora a LOCPS mantenha a sua especificidade.

Ficou evidenciado que a versão final da LOCPS apresenta os parâmetros psicométricos em níveis aceitáveis, legitimando, portanto, o seu uso para a avaliação do lócus de controle no contexto da saúde. Assim, a Tabela 3 apresenta as estatísticas descritivas das pontuações para fins de referência para os profissionais que venham a utilizá-la.

Tabela 3 - Estatísticas descritivas das pontuações na versão final da Escala LOPCS (N=266).

\begin{tabular}{lcccc}
\hline Pontuaçoes & Mínimo & Máximo & Média & Desvio padrão \\
\hline Internalidade total & $-8,5$ & 24 & 12,28 & 5,76 \\
Internalidade & 12 & 30 & 28,08 & 2,70 \\
Outros poderosos & 6 & 30 & 19,08 & 5,18 \\
Sorte & 6 & 28 & 12,52 & 5,76 \\
\hline
\end{tabular}

\section{Discussão}

Seguindo as recomendações apontadas na literatura acerca da conveniência de se usar instrumentos específicos na investigação das crenças e das atitudes e dos seus efeitos sobre os comportamentos na saúde, o propósito inicial da pesquisa foi adaptar para o contexto brasileiro uma escala de avaliação do lócus de controle parental na saúde. Ao longo do processo de investigação verificou-se, entretanto, a necessidade de criação de novos itens que melhor representassem o construto em nosso país. As análises de juízes e semântica contribuíram substancialmente para o processo de construção da nova escala, indicando serem procedimentos metodológicos bastante pertinentes em pesquisas que se propõem adaptar ou construir novos instrumentos de medida.

Do ponto de vista empírico, a investigação do poder de discriminação dos itens e as análises da validade (fatorial e de critério) e da precisão possibilitaram chegar a uma versão final da escala, revelando-se adequada em termos psicométricos. Os 18 itens finais se mostraram bastante discriminativos, variando as correlações item-total entre 0,29 e 0,65. Os índices de precisão pelo método do alfa de Cronbach para as três dimensões podem ser considerados satisfatórios para escalas do tipo da LOCPS, pois ficaram acima de 0,60. Destaca-se que a subescala Externalidade acaso/sorte foi a que apresentou maior grau de consistência interna $(0,80)$.
Ao proceder uma análise comparativa dos parâmetros psicométricos da LOCPS com os dois instrumentos de avaliação do Lócus de Controle reportados na literatura nacional, verifica-se que os índices de consistência interna apresentados por esta escala foram superiores aos da Escala Multidimensional de Lócus de Controle de Levenson (Dela Coleta, 1987) e aos da Escala de Lócus de Controle de Pacientes Portadores de Insuficiência Renal Crônica (Peres, 1993). Do ponto de vista da validade fatorial, constatou-se que a escala não é unidimensional, característica também presente na maioria dos instrumentos nacionais construídos para avaliar o construto lócus de controle (Dela Coleta, 1987, 1992; La Rosa, 1991; Pasquali, Alves \& Pereira, 1998; Peres, 1993).

\section{Conclusão}

O estudo alcançou o objetivo proposto, qual seja, disponibilizar para os pesquisadores e profissionais uma escala brasileira que permita investigar o lócus de controle em contextos específicos, no caso, o dos cuidadores no que diz respeito à saúde de suas crianças. Ressalta-se, no entanto, que em se tratando de um primeiro estudo, é recomendável a continuidade de pesquisas com a referida escala em outras populações-alvo, tendo em vista, particularmente, que o estudo da validade de critério apresentado não demonstrou bons índices para todas as dimensões. 


\section{Referências}

Dancey, C. \& Reidy, J. (2006). Estatística sem matemática para psicologia. Porto Alegre: Artmed.

Dela Coleta, M. F. (1987). Escala multidimensional de lócus de controle de Levenson. Arquivos Brasileiros de Psicologia, 39(2), 79-97.

Dela Coleta, M. F. (1992). Lócus de controle e satisfação conjugal. Psicologia: Teoria e Pesquisa, 8(2), 243-252.

Furnham, A. \& Steele, H. (1993). Measuring locus of control: A critique of general, children's, health- and work-related locus of control questionnaires. Brithish Journal of Psychology, 84, 443-479.

La Rosa, J. (1991). Lócus de controle: uma escala de avaliação. Psicologia: Teoria e Pesquisa, 7(3), 327-344.

Maisto, A. A. \& German, M. L. (1981). Maternal Locus of control and developmental gain demonstrades by high risk infants: A longitudinal study. The Journal of Psychology, 109, 213-221.

Pasquali, L. (1999). Instrumentos psicológicos: manual prático de elaboração. Brasília: LABPAM/IBAPP.

Pasquali, L., Alves, A. R. \& Pereira, M. A. M. (1998). Escala de Lócus de controle ELCO/TELEBRÁS. Psicologia: Reflexão $e$ Crítica, 11(2), 363-378.

Peres, E. M. (1993). Escala para Estudo do "Lócus de Controle" de Pacientes Portadores de Insuficiência Renal Crônica. Revista de Enfermagem da UERJ, 1(1),100-107.

Pietro, G. \& Muñiz, J. (2000). Um modelo para evaluar la calidad de los tests utilizados em España. Obtido na World Wide Web em outubro de 2000, [bttp:// www.cop.es/tests/ modelo.htm].

Rotter, J. B. (1966). Generalized expectancies for internal versus external control of reinforcement. Psychological Monographs, 80 (1), $1-28$.

Rotter, J. B. (1975). Some problems and misconceptions related to the construct of internal versus external control of reinforcement. Journal of Consulting and Clinical Psychology, 43(1), 56-67.

Rotter, J. B. (1990). Internal versus external control of reinforcement. American Psychologist, 45(4), 489-493.

Souza, M. A. (1995). Funcionamento intelectual de drogadictos através do Rorschach. Boletim de Psicologia, 103, 105-124.

Tamayo, A. (1989). Validade fatorial da escala Levenson de Lócus de Controle. Psicologia: Teoria e Pesquisa, 5(11), 111-122.

Tinsley, B. J. \& Holtgrave, D. R. (1989). Maternal health locus of control beliefs, utilization of childhood preventive health services, and infant health. Developmental end Behavioral Pediatrics, 10(5), 236-241.

Wallston, B. S., Wallston, K. A., Kaplan, G. D. \& Maides, S. A. (1976). Development and validation of the Health Locus of Control (HLC) Scale. Journal of Consulting and Clinical Psychology, 44(4), 580-585.

Recebido em dezembro de 2007 Reformulado em maio de 2008 Aprovado em setembro de 2008

Sobre os autores:

Márcia Maria Magrille de Cerqueira é mestre em Psicologia Social pela Universidade Federal de Minas Gerais/ MG e analista social na Companhia Urbanizadora de Belo Horizonte - Urbel.

Elizabeth do Nascimento é doutora em Psicologia pela Universidade de Brasília/DF, professora do curso de graduação e do programa de pós-graduação do Departamento de Psicologia da UFMG. Membro fundadora do Laboratório de Avaliação das Diferenças Individuais (LADI). 


\section{Anexo - Escala de Lócus de Controle Parental na Saúde}

Márcia M. Magrille Cerqueira

\section{Instruções}

Universidade Federal de Minas Gerais

A seguir, apresentamos algumas afirmações sobre a saúde das crianças. Você provavelmente concordará com algumas e discordará de outras. Não existem respostas certas ou erradas. Queremos apenas saber o quanto você concorda ou discorda dessas opiniões. Leia cada afirmação cuidadosamente e marque, no espaço adequado, a opção que melhor representa aquilo que você acredita. As opções são as seguintes:

\begin{tabular}{|c|c|c|c|c|}
\hline \multicolumn{4}{|c|}{ Opções de resposta } \\
\hline 1 & $\mathbf{2}$ & $\mathbf{3}$ & $\mathbf{4}$ & $\mathbf{5}$ \\
\hline $\begin{array}{c}\text { Discordo } \\
\text { Totalmente }\end{array}$ & $\begin{array}{c}\text { Discordo } \\
\text { um pouco }\end{array}$ & $\begin{array}{c}\text { Indeciso } \\
\text { (não concordo nem } \\
\text { discordo) }\end{array}$ & Concordo um pouco & $\begin{array}{c}\text { Concordo } \\
\text { totalmente }\end{array}$ \\
\hline
\end{tabular}

Procure responder a todas as afirmações de acordo com a primeira impressão que tiver. Evite corrigir as suas respostas.

Afirmações

1. Sempre que meu filho passa mal, o melhor a fazer é levá-lo imediatamente a um hospital.

2. A saúde do meu filho depende da sorte.

3. Posso fazer muitas coisas para que meu filho fique bom quando ele adoece.

4. Confio inteiramente no médico, ele estudou e sabe o que é melhor para a saúde do meu filho.

5. Não importa o que eu faça, meu filho fica doente por falta de sorte.

6. Posso fazer muitas coisas para manter a saúde do meu filho.

7. Na maioria das vezes, quem pode cuidar dos dentes do meu filho são os dentistas.

8. A saúde do meu filho depende, em grande parte, de como eu cuido dele.

\begin{tabular}{|l|l|l|l|l|}
\hline \multicolumn{5}{|c|}{ Opções de resposta } \\
\hline 1 & 2 & 3 & 4 & 5 \\
\hline 1 & 2 & 3 & 4 & 5 \\
\hline 1 & 2 & 3 & 4 & 5 \\
\hline 1 & 2 & 3 & 4 & 5 \\
\hline 1 & 2 & 3 & 4 & 5 \\
\hline 1 & 2 & 3 & 4 & 5 \\
\hline 1 & 2 & 3 & 4 & 5 \\
\hline 1 & 2 & 3 & 4 & 5 \\
\hline
\end{tabular}




\begin{tabular}{|c|c|c|c|c|}
\hline $\mathbf{1}$ & $\mathbf{2}$ & $\mathbf{3}$ & $\mathbf{4}$ & $\mathbf{5}$ \\
\hline $\begin{array}{c}\text { Discordo } \\
\text { Totalmente }\end{array}$ & $\begin{array}{c}\text { Discordo } \\
\text { um pouco }\end{array}$ & $\begin{array}{c}\text { Indeciso } \\
\text { (não concordo nem } \\
\text { discordo) }\end{array}$ & Concordo um pouco & $\begin{array}{c}\text { Concordo } \\
\text { totalmente }\end{array}$ \\
\hline
\end{tabular}

Afirmações

9. Crianças que nunca adoecem contam com a sorte.

10. Posso fazer alguma coisa para evitar que meu filho tenha cáries.

11. Quando meu filho se machuca, o melhor a fazer é levá-lo ao médico.

12. Os acidentes que acontecem com as crianças são obra do destino.

13. Posso fazer muitas coisas para evitar que meu filho sofra acidentes.

14. Na maioria das vezes, quem pode evitar que meu filho fique doente são os médicos e as enfermeiras.

15. Se meu filho tem azar, nada que eu ou os médicos façam pode evitar que ele fique doente.

16. Posso tomar cuidados para que meu filho tenha uma boa alimentação.

17. É papel dos nutricionistas garantir que meu filho tenha uma alimentação saudável.

18. Se meu filho tem que adoecer, ele adoece e não há nada nem ninguém que possa evitar.

\begin{tabular}{|l|l|l|l|l|}
\multicolumn{6}{|c|}{ Opções de resposta } \\
\hline 1 & 2 & 3 & 4 & 5 \\
\hline 1 & 2 & 3 & 4 & 5 \\
\hline 1 & 2 & 3 & 4 & 5 \\
\hline 1 & 2 & 3 & 4 & 5 \\
\hline 1 & 2 & 3 & 4 & 5 \\
\hline 1 & 2 & 3 & 4 & 5 \\
1 & 2 & 3 & 4 & 5 \\
\hline 1 & 2 & 3 & 4 & 5 \\
\hline & 2 & 3 & 4 & 5 \\
\hline & & & 5 \\
\hline
\end{tabular}


